\title{
GRAFTING METHODS FOR THE DOUGLAS FIR
} By A. L. ORR-EWING ${ }^{2}$ and D. C. PRIDEAUX ${ }^{3}$

A. L. Orr-Ewing came to Canada from Scotland, 1933, B.Sc.F. Edinburgh University 1939, Imperial Forces 1939-1946, Forestry Commission 1946 to 1947. Returned to Canada 1948, Research Division, B.C. Forest Service, 1948 to present time. M.F. University of California, 1951, Ph.D. University of British Columbia, 1956.

D. C. Prideaux, Imperial Forces 1939-1945, came to Canada from England 1947, worked in horticultural fields 1947-1951, Research Division, B.C. Forest Service 1951 to present time. Research nurseryman 1958.

\section{ABSTRACT}

Grafting is a valuable technique for foresters interested in improving seed-quality as the inherent characteristics of selected trees can be preserved indefinitely for breeding and seed orchards. Dormant scions of the Douglas fir can be collected in the winter and early spring by either climbing or shooting off branches with a rifle. They are stored until the rootstock is in an actively growing condition and are then either grafted in a greenhouse or outside. The cleft and crown veneer graft methods have been found the most suitable for this species. The possibilities of early cone production after grafting appear promising.

\section{INTRODUCTION}

Vegetative propagation by grafting - the joining together of the scion or aerial part of the selected parent to the rootstock, (the root-bearing plant) has been standard practice among horticulturists for a great many years. The scion retains all the inherent characteristics of the parent so that grafting is a most valuable technique for perpetuating a particular plant, shrub, or fruit tree. The possibilities of extending this technique to forest practice in order to conserve the germplasm of outstanding trees has been little appreciated by foresters in Canada. The field of forest genetics, however, should have a wide future in this country, and grafting will then become common practice. Although much has been written on grafting methods with conifers in recent years, scant reference has been made to the Douglas fir (Pseudotsuga menziesii (Mirb) Franco). Grafting methods, moreover, will vary with the species concerned and the local conditions under which it takes place so that the following pages may be of interest to others working with the Douglas fir. No attempt, however, has been made to deal with such important basic problems of grafting as the relationship between rootstock and scion, but it is hoped that more detailed studies will follow.

\section{Scion Collection and Storage}

Successful grafting depends upon many factors other than the actual technique of grafting itself, and the first concerns the collection of the scions.

\footnotetext{
${ }^{1}$ B.C. Forest Service Publication T.52. Received for publication March $23,1959$.

a Forester, Research Division B.C. Forest Service, Victoria.

Forest Assistant, Research Division B.C. Forest Service, Duncan.
} 
These are collected in the winter and early spring when the buds are dormant and, as it is preferable to graft with fresh material, collection is usually timed so that the storage period is as short as possible. If the scions are to be grafted outside, the material is collected in late March and early April, but, if they are to be grafted in a greenhouse, they can be collected at any time from late fall to early spring depending upon the development of the rootstock. The scions should be cut longer than actually necessary. They will not dry out readily and the extra length is of assistance to the grafter. They should be vigorous, with healthy vegetative buds and, if possible, originate from the current growth of the tree. They should also be collected from the upper crown as both the age of the scion wood and its position on the tree can influence later development. This factor should not be overlooked in clonal tests. Another important reason for collecting scions from near the top of a tree is that they come from the cone-bearing part of the crown. There is already encouraging evidence that such scions can produce both cones and pollen at an early age after grafting. This, of course, is a very important consideration in both controlled breeding and seed orchard establishment.

Wherever possible, the scions are removed by the collector after climbing the tree, but this is much more difficult with older trees and those in the more inaccessible locations. In such cases, the scions are shot down with a .22 semi-automatic rifle fitted with four-power telescopic sights. A Mossberg long rifle has been used for this work, as it has a forward grip which is most useful for steadying the rifle when aiming. The magazine holds seven bullets and the hollow-pointed mushroom type has been found the most suitable for breaking off small branches. It is not easy to shoot down scions from high trees under the wet and windy conditions frequently found in the winter and early spring but, with practice, it is by no means impossible. The amount of ammunition used will naturally depend upon the skill of the collector but needless waste can be avoided. It is pointless, for example, to try to shoot from a free standing position as a rifle cannot be held steadily enough for any length of time and the collector must brace himself against some object for support. It is also pointless to try to shoot on very wet and windy days as the sights become blurred and there is too much branch movement. It is not too difficult, however, to co-ordinate aiming with branch movement if the wind is not too strong. Finally, it is most important to ensure, at frequent intervals, that the telescopic sights are correctly aligned. This can be done quickly by firing a few sighting shots at a fixed target approximately the same distance away as the height of the tree.

The importance of care in the handling of a loaded rifle cannot be overemphasized, as the collector is usually alone and at some distance from the nearest road. To avoid needless accidents, the rifle should only be loaded when a position has been found from which to fire. The safety catch should not be released until just before the trigger is pulled. The collector should also ensure that he has a clear field of fire towards the branch at which he aims, as an intervening branch of another tree can cause dangerous ricochets. He should also keep himself oriented to logging and other operations in the 
forest as a .22 bullet has a range of one mile. If the collector is alone, he should, of course, leave behind some details of where he will be, as unforeseen accidents with firearms can occur.

It is advisable to clear the ground immediately below the tree so that the material shot down can be more readily located and not become mixed with other material brought down by the wind. When sufficient material has been collected, it should be carefully packed in wet moss and placed in polyethylene bags. These are finally placed in storage at $34^{\circ} \mathrm{F}$. This temperature has proven adequate for material stored up to eight weeks and, at the present time, there has been no necessity for longer periods of storage.

\section{CARE OF THE ROOTSTOCK}

Successful grafting is also dependent upon the quality and pre-treatment of the rootstock upon which the scions will be joined. Much has still to be learned about this particular phase of grafting. In the past, $2+0$ seedlings of a known lot have been selected for rootstock in the nursery, the criteria for selection being vigor and form. For greenhouse grafting, these seedlings are potted in the spring and then bedded down under shade frames in the nursery until required. For outside grafting, the $2+0$ seedlings are planted at two-foot spacing in the spring and are used as rootstock the following year. In both cases, however, the rootstock becomes too large and, if potted, is liable to become pot-bound. In the future, $1+0$ seedlings will be used and efforts will be made to both select and grow special rootstock, as the present practice of selecting seedlings from a common seed lot can be much improved. The rootstock should be trimmed up sometime before grafting; double leaders, if any, should be removed and the lower branches pruned off if the veneer side graft method is to be used.

Correct timing of rootstock development with scion collection is also important as the former must not be in a dormant condition at the time of grafting. The buds should be swollen and there should be sufficient cambial activity to allow the bark to slip readily.

With outside grafting, little can be done to accelerate this activity and, under local conditions, grafting is not possible before the second or third week of April. There is considerable variation in the degree of bud development in the rootstock. Such variation could, no doubt, be reduced by more careful selection of rootstock which could be directed towards the selection of seedlings that flush early. Greenhouse grafting is much more flexible as the rootstock can be brought in from the nursery and, with experience, forced into activity so that grafting can be spread over the winter months to alleviate the pressure of other spring work.

The techniques for breaking dormancy in the Douglas fir, however, are still largely unknown and require much further study. It is evident that prechilling is necessary. Rootstock brought into an unheated greenhouse in late February, 1956, for example, was ready for grafting one month later, whereas rootstock brought in in mid-December, 1958, was barely ready for grafting two months later. This rootstock, moreover, was placed in benches with a 
heating cable held at $70^{\circ} \mathrm{F}$. and also given an extended-day length of sixteen hours. As the winter temperatures on Vancouver Island can be very variable, artificial pre-chilling of rootstock may be necessary.

\section{Grafting Methods}

The grafting methods used with forest trees are almost all modifications of those used in horticulture which are described in detail in The Grafter's Handbook'. Before discussing those methods found most applicable to the Douglas fir, brief mention should be made of grafting equipment. A knife of good-quality steel is essential. The type used has a four-inch flat-sided blade which must be kept both sharp and clean when grafting. Alcohol should be used to keep the blade free from resin. An oil stone, pruning knife with curved blade, secateurs, raffia and/or rubber grafting bands, horticultural wax, brush and wax melter are other necessary accessories. For outside, a portable lantern-type wax melter is very useful.

The following grafting methods have been used with the Douglas fir.

\section{Veneer side graft}

This method, which is used a great deal with conifers, has been restricted to greenhouse grafting as it has not proved successful outside under local conditions. The needles are first stripped off the lower part of the scion which should be vigorous and from three to four inches long. Next, an even, sloping cut is made along one side and the base is trimmed to form a lip. A similar cut is then made on the rootstock so that the cambiums on both the scion and rootstock are exposed (Fig. 1). These cuts should be made as quickly as possible and not handled. The scion is next fitted into the rootstock so that the cambiums match on at least one of the sides (Fig. 2); it is then tied closely to the rootstock with wet raffia (Fig.3). The binding is finally waxed evenly over the whole surface so that water cannot enter. The development of the scion after grafting will vary, depending upon many factors, and weak scions are apt to be "walled off" by the callus tissue of the rootstock, unless the latter is cut back to prevent it becoming too vigorous. The raffia will also have to be cut or it will strangle the developing scion which should then be lightly retied to the rootstock (Fig. 4). The grafted material requires frequent attention after grafting as it must be kept well watered and the humidity in the greenhouse should be kept reasonably high.

The material is moved out of the greenhouse and bedded down under shade frames in the nursery as soon as the weather is suitable and there is little danger of spring frosts. Under local conditions, this will be towards the end of May. In future, the grafted material will be removed from the pots at this time and planted out to allow for more vigorous root development. Depending upon the development of the scion, the rootstock is gradually cut back during this period until, finally, only a short stub will remain. It is advisable to tie the scion lightly to this until it is well established. The stub can then be cut right back with a sloping cut away from the scion, and the surface waxed.

\footnotetext{
'Garner, R. J. 1958. The Grafter's Handbook. Faber \& Faber Ltd. London. Rev. Ed.
} 
Veneer side grafting has given a high rate of survival in the greenhouse but there has been considerable mortality after the grafted material has been finally planted out the spring following grafting. The summers have been very dry and it has not been possible to give the material any attention, other than weeding. It is possible that the rootstock should be cut back more gradually, but field survival has been considerably lower than that of scions either cleft- or veneer-crown grafted in the greenhouse. The grafted material also needs staking and considerable weeding when planted out. Therefore, in future, this method of grafting will probably be restricted to special material which cannot be grafted by the other methods.

\section{Veneer crown graft}

This method has been successfully used where the scion material has a smaller diameter than that of the rootstock, which is often the case in grafting on established stock in a seed orchard. The top of the rootstock is removed, as previously, and a short cut is made on one of the sides to expose the cambium. A similar cut is then made on the scion and the needles are removed as before (Fig. 13). The scion and the rootstock are then fitted together so that the cambium of both will match on one of the sides (Fig. 14). The scion is next secured with grafting bands (Fig. 15), waxed and enclosed with a polyethylene bag, a Kraft paper bag will again be necessary if grafting is outside. The developing scions have to be regularly checked, as with cieft grafting, and the rootstock gradually cut back. Scions grafted onto planted stock can develop very rapidly. For example, one grafted in Apri], 1957, grew 30 inches the first growing season. It was then planted out in the fall and grew another 21 inches the following year (Fig. 16). Lammas growtb was produced on both occasions.

\section{CAPTIONS FOR PAGES $197-200$}

FIGURE 1: A veneer side graft; the sloping cuts have been made on both rootstock and scion. FIGURE 2: Matching the cambiums of rootstock and scion. FIGURE 3: The scion has been tied in place with raffia.

FIGURE 4: A scion three months after grafting, the rootstock has been gradually cut back.

FIGURE 5: Cleft grafting-matching the rootstock and scion; the buds of the former are well developed.

FIGURE 6: The rootstock and scion have been cut to size.

FIGURE 7: The vertical cut is carefully made on the rootstock.

FIGURE 8: The first sloping cut is made on the scion.

FIGURE 9: The wedge-shaped scion is inserted into the cut of the rootstock.

FIGURE 10: The scion is firmly secured with a rubber grafting band.

FIGURE 11: A polyethylene bag is placed over the scion after waxing.

FIGURE 12: A scion two feet in height five months after grafting; the original cleft is indicated. Note the lammas growth.

FIGURE 13: A crown veneer graft. Cuts have been made on both rootstock and scion.

FIGURE 14: The cambium on one side of the scion is matched with that of the rootstock.

FIGURE 15: The scion is secured to the rootstock with a grafting band.

FIGURE 16: A scion two growing seasons after crown grafting. The graft junction is indicated by the ruler. 

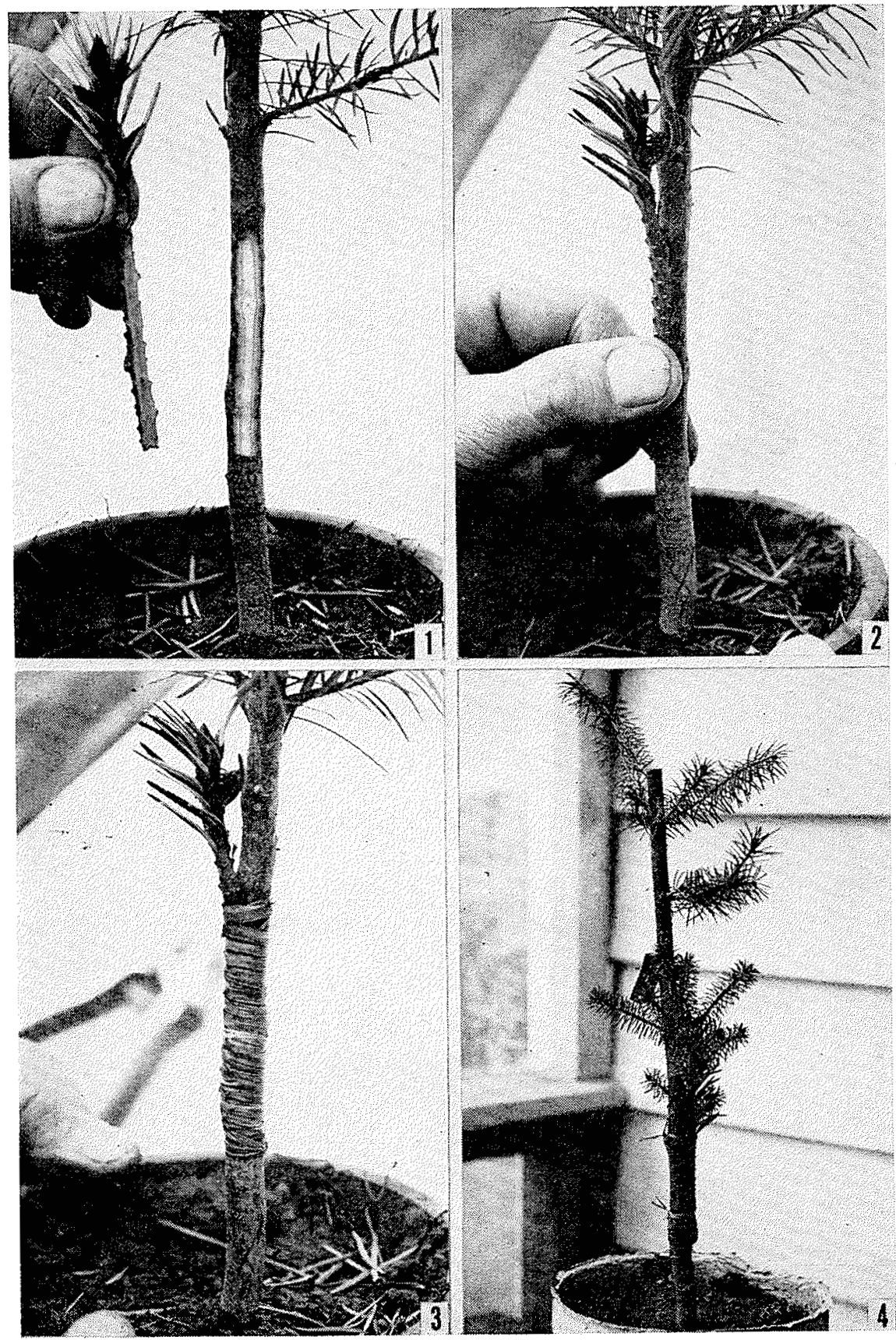

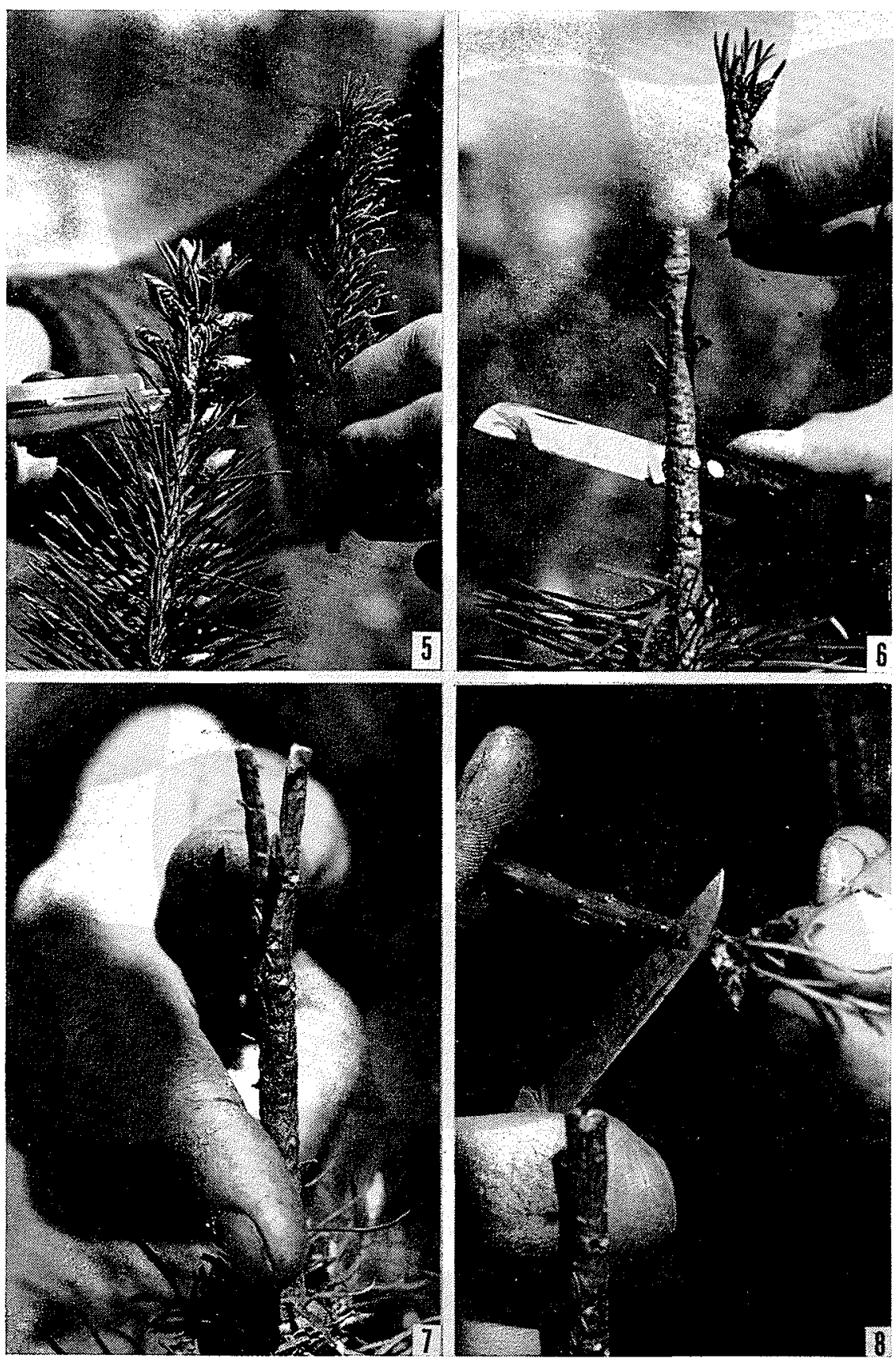
SEPTEMBER, 1959
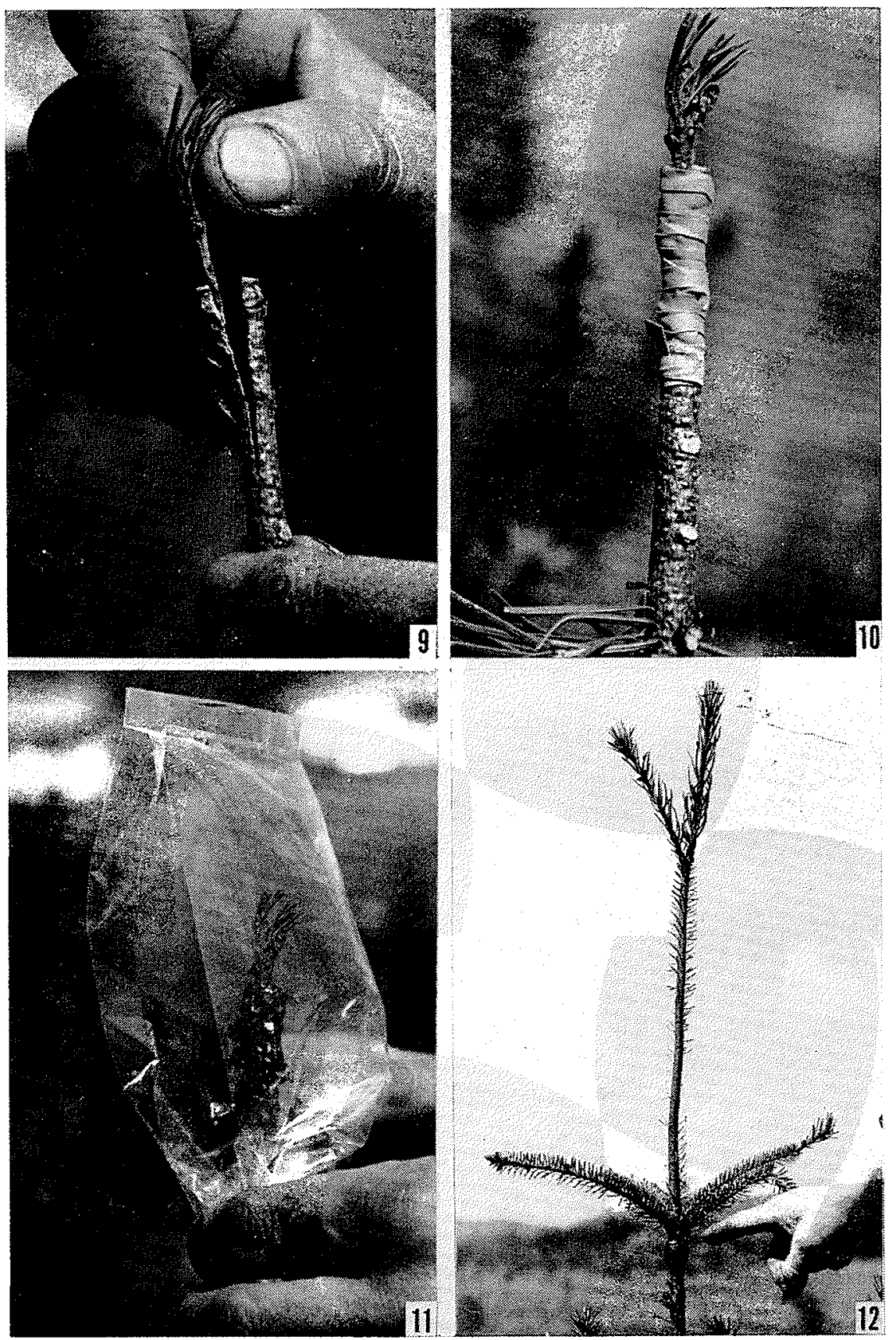


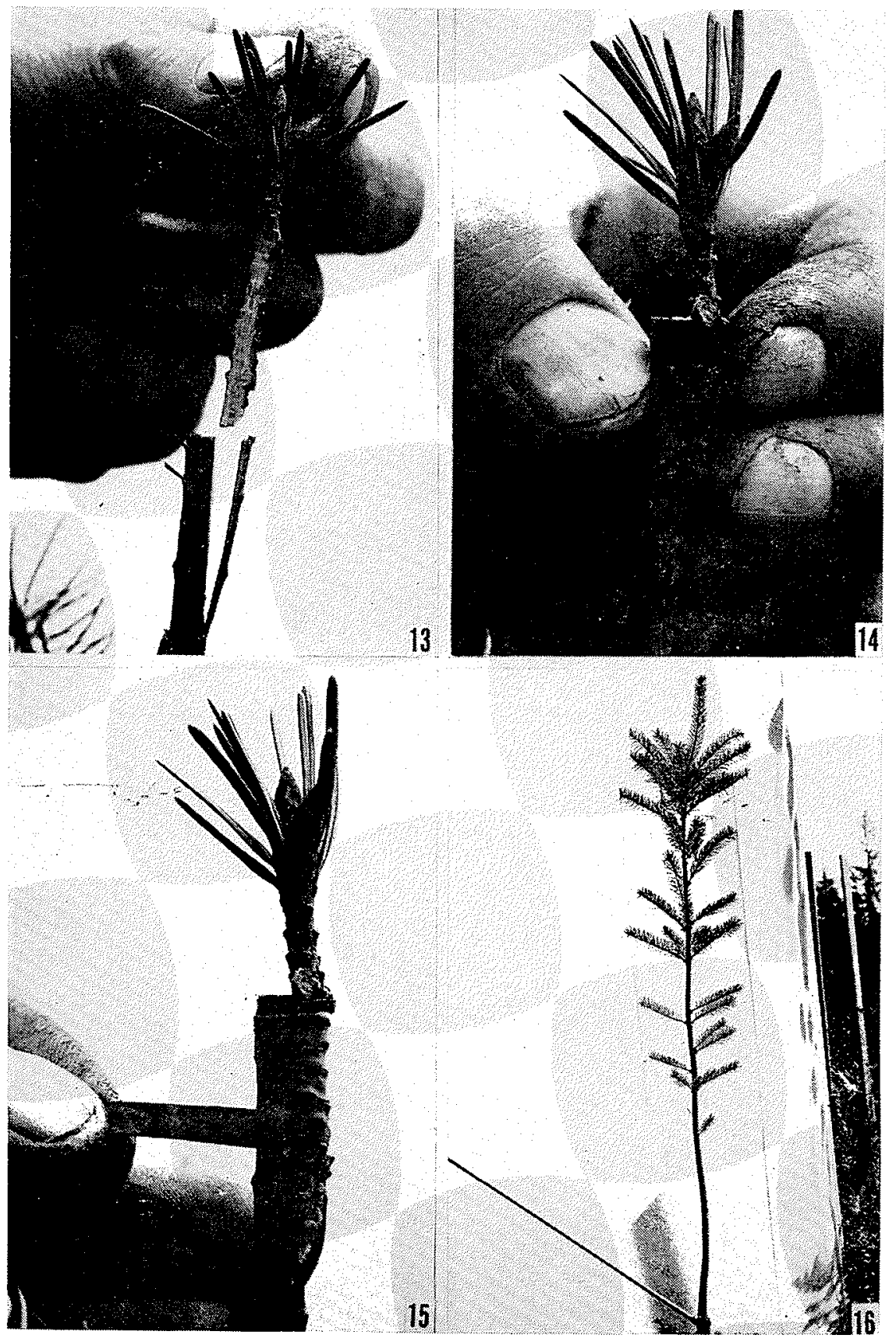




\section{Cleft grafting}

This method has been used successfully in both greenhouse and outside grafting and Figures 5 to 12 were all taken outside in the nursery in April, 1958. The scion and rootstock are first matched for size (Fig. 5) and material as large and as vigorous as that in the photograph can be divided to make two or three suitable scions, as long as there are sufficient vegetative buds. The top of the rootstock is then removed and this cut should be made in the current growth, if possible. The scion is then cut to about two inches in length and the needles are removed as shown. The needles are also removed from the top two inches of the rootstock (Fig. 6). Next, a clean, vertical cut is made in the rootstock to a depth of two inches (Fig. 7) and the scion is carefully cut on both sides to form a wedge (Fig. 8). It is then held by the uncut portion and carefully inserted in the cut on the rootstock which is held apart with a knife (Fig. 9). The cambiums of both scion and rootstock are matched on both sides and the grafted material tied with grafting bands (Fig. 10). The shoulders and sides of the graft are finally waxed and enclosed in a polyethylene bag (Fig. 11). The bags maintain a high humidity around the scion and are a necessity for outside grafting under local conditions where the weather in April and May is often sunny with drying winds. Scions which have not been covered in this manner have all died. A Kraft paper bag, with ventilation holes facing the north, is finally placed over the polyethylene bag to provide the necessary shade for outside conditions. The temperatures around the scion will otherwise become lethal in sunny weather.

The grafted material has to be watered and regularly checked to ensure that the developing scion is not being strangled by the grafting bands. The polyethylene bag is loosened and finally removed as the buds break but the Kraft bag remains until the scion is well developed, as it can be damaged by a hot sun. This development period varies between six and eight weeks. Outside grafting is naturally dependent upon the weather and dull days are preferable to sunny ones when grafting must be done quickly to prevent the cut surfaces from drying out. No grafts should be made in wet weather. The branches of the rootstock below the scion should be gradually pruned off and the stem left clean, once the scion is well established. Vigorous scion material on planted rootstock can grow very rapidly and heights of two feet or more at the end of the first growing season are not uncommon (Fig. 12). The stock can be safely planted out in the fall following grafting.

Succulent cleft grafting, where both scion and rootstock are in active growth, should be briefly mentioned as it has been tried on a small scale with some success in both the greenhouse and outside. The scions which are fully flushed are carefully grafted in the usual manner as soon as possible after collection. The merit of succulent grafting is that it can be carried out during the summer months.

\section{Precocious Cone Bearing After Grafting}

It has already been mentioned that the scions should be collected from the upper crown of the parent tree, this being the cone-bearing part. Both male and female cone buds are often found on the scions when the latter are collected 
but, as their development is inclined to weaken that of the vegetative buds, they are usually removed when grafting. Some male and cone buds, however, have been allowed to remain on scions which were veneer side grafted in order to study their later development. The male cones have not developed sufficiently to produce pollen, but the female buds will develop into small cones with undersized seeds. It is very probable that with proper care and nutrition these cones could develop normally without weakening the scion and, moreover, could be pollinated.

Cone production, the year after grafting, is of more interest as the primordia will have been initiated after the scion was removed from the tree. There has been one case of this occurring to date. A scion, grafted in March, 1957 , on to $2+0$ rootstock and planted out the following spring, produced a normal-sized cone and seven normal pollen cones that same year. The cone contained 21 seeds, seven of which were found to be viable, probably as a result of wind pollination. The following year another grafted scion produced a seed cone without any stimulus from fertilizers.

The time interval between planting and the first production of cones is a major problem to the tree-breeder and these early indications in the Douglas fir are definitely encouraging.

\section{ACKNOWLEDGEMENTS}

Valuable advice on grafting techniques was given by $\mathrm{Mr}$. $\mathrm{H}$. Varekamp, Forest Assistant with the Research Division from August, 1955, to February, 1957. The photographs and plates were made by the Public Information Division of the B.C. Forest Service. 